\title{
Death from AIDS is preventable, so why are people still dying of AIDS in Europe?
}

V Delpech (valerie.delpech@phe.gov.uk)1, J Lundgren²

1. Public Health England, London, United Kingdom

2. Department of Infectious Diseases, Rigshospitalet, University of Copenhagen, Denmark

Delpech V, Lundgren J. Death from AIDS is preventable, so why are people still dying of AIDS in Europe?. Euro Surveill. 2014;19(47):pii=20973. Available online: http://www.eurosurveillance.org/ViewArticle.aspx?Articleld=20973

It is almost two decades since life-saving treatment for human immunodeficiency virus (HIV) became available. Life expectancy among people living with HIV, for whom optimal therapy is initiated timely, is now close to that of the general population [1]. Despite this, an estimated 1.6 million people died from acquired immunodeficiency syndrome (AIDS)-related illnesses globally in 2012, and the number who died within the World Health Organization (WHO) European Region reached almost 100,000 [2]. A large proportion of these deaths occur in the eastern part of the Region, and without changes in the HIV response, the death toll in this region is likely to continue to increase in the coming years [3]. Conversely, in the west, the risk of AIDSrelated death continues to decline [3], reflecting some positive progress.

The majority of AIDS-related deaths would be preventable if available evidence were to be fully implemented. Research findings reported in this issue of Eurosurveillance exemplify the challenges we face as we enter the fourth decade of the epidemic. Better and more comprehensive testing strategies aimed at persons most at risk of contracting HIV are needed, linked to HIV care and treatment programs. Implementation research needs to be at the core of the HIV response.

Diagnosis at a late stage of HIV infection and subsequent delays in starting treatment with antiviral agents are the important factors for the high death toll in parts of Europe and certain subgroups. Pharris et al. in this issue present the latest trends in HIV diagnoses in the European Union/ European Economic Area [4] and show that, based on countries where information is available, about half of the 300,000 people diagnosed with HIV over the past decade had a CD4 cell count of 350 copies $/ \mathrm{mL}$ or less at the time of diagnosis (defined as 'late diagnosis'). Consequently, their risk of death within the year of their diagnosis was more than 10 times higher than that of individuals diagnosed early and entering care promptly [5]; those diagnosed late aged 50 years and over carried an even greater risk [6]. This is of particular concern given the increase in the number of persons diagnosed at an older age in Europe with almost two thirds diagnosed at a late stage of infection (personal communication Anastacia Pharris, November, 2014).

Encouraging signs of an overall decline in late diagnoses in western Europe in recent years should be interpreted with caution as this may be due to a modest decline in the number of new HIV diagnoses among migrants, the population with the highest proportion of late presenters, rather than improvements in earlier diagnosis [4]. Data on late diagnosis in the eastern part of the WHO European region are largely lacking and where available above rates reported in the west [3].

In addition to the increased risk of developing AIDS, early death and increased health costs associated with late presentation for HIV care, people living with HIV who remain unaware of their HIV positive status are more likely to pass on their infection to their sexual partners [7]. HIV treatment has public health benefits in reducing onward transmission and preventing new cases of HIV, as well as clinical benefits for the individual people living with HIV in restricting the progression of HIV $[7,8]$. Sadly, while there are indications that treatment uptake has improved over the past decade, there are few signs that HIV transmission is declining across Europe, and for some groups, namely men who have sex with men (MSM), the latest information points to increases in new infections [4]. This is despite the fact that the late presentation statistics for this population are among the most favourable with only around $30-40 \%$ presenting late for care across countries in the European Union and European Economic Area (EU/ EEA) [4]. The situation in the eastern part of the WHO European region continues to deteriorate with increasing HIV incidence, mostly confined to injecting drug users and their sexual partners [3].

Routine information on HIV incidence among most at risk populations is crucial in informing the HIV response. Studies in this issue from Italy and Spain report high levels of HIV transmission among men who have sex with men, sex workers and persons who inject drugs (PWID) $[9,10]$. While it is reassuring that 
a low incidence was found among prisoners in Estonia [11], imprisonment of people who inject drugs and prohibition of opioid substitution therapy further east has fuelled the epidemic [3].

So what are the implications from these findings? Has the Dublin Declaration on Partnership to Fight HIV/ AIDS in Europe and Central Asia [3] which set out a plan to combat HIV over the past 10 years failed? While some successes have been realised, clearly the analyses on late diagnosis presented here indicate that the challenges of diagnosing individuals at an early stage of HIV infection and ensuring linkage to HIV care have not been met across Europe. This is despite a growing body of scientific evidence on barriers to testing among most at-risk populations and effective ways of addressing them. For instance, awareness and education of healthcare staff can substantially increase the offer and acceptance of HIV testing in a wide range of settings in a non-discriminatory way and help normalise the testing process [12]. Novel methods to promote testing such as home sampling and testing kits are showing promise in reaching key populations [13]. Initiatives such as this week's European HIV testing week provide an opportunity to share and disseminate good practice and scale up testing efforts [14].

A core component of evaluating these novel testing approaches should include their ability to link and retain people living with HIV and in appropriate HIV treatment, care and support programmes. A proportion of people entering HIV care late are actually aware of their HIV-positive status, but failed to access care when first diagnosed. Whereas this is true for a relatively small fraction of late presenters in the western and central parts of Europe, [5] poor linkage and retention into care including adequate provision of HIV treatment and opioid substitution therapy are major shortcomings in the HIV response in the eastern part of the WHO European region [3].

UNAIDS has set ambitious targets for all countries: by 2020 , governments will commit to ensuring that in any key population and any country in Europe, $90 \%$ of people living with HIV will know their HIV status, $90 \%$ of people with diagnosed HIV infection will receive sustained antiretroviral therapy, and $90 \%$ of people receiving antiretroviral therapy will have durable viral suppression [15]. These targets, while highly aspirational, provide a basis for concerted action. A first step is to require that countries have adequate and preferentially harmonised information systems to monitor progress in reaching these targets. However, data on CD4 count at diagnosis were only available from $14 \mathrm{EU} /$ EEA countries to track late diagnosis, and even fewer countries have estimates of the number of persons living with diagnosed and undiagnosed HIV and receiving treatment [4]. Of particular concern is the lack of accurate information on the most at-risk and vulnerable populations.
Government leadership in partnership with civil society has been and should continue to be a critical component to the HIV response. Of paramount importance is the implementation of anti-discriminatory and protective laws and policies that ensure the human rights of all persons living with HIV and promotes their access to HIV testing and free (or affordable) healthcare regardless of sexuality, drug taking or residency status. Stigma and discrimination remain important barriers to timely HIV testing and access to healthcare in many parts of Europe. While test-and-treat policies are likely to be an essential component of the HIV response over the next decade, these should not be the only focus. Political and financial investment in a range of comprehensive HIV prevention strategies need to be tailored to meet the specific and nuanced needs of key populations most vulnerable to contracting HIV such as men who have sex with men, migrants, people in prison, sex workers, and people who inject drugs. Implementation research in each of these areas is essential to reducing onward transmission of HIV in Europe, enabling progress in the response to HIV, and continuing to steer the fourth decade of the response to HIV in Europe in the most effective direction.

Conflict of interest:

None declared.

\section{References}

1. May M, Gompels M, Delpech V, Porter K, Post F, Johnson M, et al. Impact of late diagnosis and treatment on life expectancy in people with HIV-1: UK Collaborative HIV Cohort (UK CHIC) Study. BMJ. 2011;343:d6016. http://dx.doi.org/10.1136/bmj. d6016

2. World Health Organization (WHO). Global Health Observatory data repository. Geneva: WHO. [Accessed: 26 Nov 2014]. Available from: http://apps.who.int/gho/data/view.main.22110

3. European Centre for Disease Prevention and Control (ECDC). From Dublin to Rome: ten years of responding to HIV in Europe and Central Asia: Stockholm, ECDC; 2014. Available from: http://www.ecdc.europa.eu/en/publications/Publications/ dublin-rome-10-years-hiv-europe-central-asia.pdf

4. Pharris A, Spiteri G, Noori T, Amato-Gauci AJ. Ten years after Dublin: principal trends in HIV surveillance in the EU/EEA, 2004 to 2013. Euro Surveill. 2014;19(47): $\mathrm{pii}=20968$.

5. Mocroft A, Lundgren JD, Sabin ML, Monforte Ad, Brockmeyer N, Casabona J, et al. Risk factors and outcomes for late presentation for HIV-positive persons in Europe: results from the Collaboration of Observational HIV Epidemiological Research Europe Study (COHERE). PLOS Med.2013;10(9):e1001510. http://dx.doi.org/10.1371/journal. pmed.1001510

6. Davis DH, Smith R, Brown A, Rice B, Yin Z, Delpech V. Early diagnosis and treatment of HIV infection: magnitude of benefit on short-term mortality is greatest in older adults. Age Ageing. 2013;42(4):520-6. http://dx.doi.org/10.1093/ageing/afto52

7. Cohen MS, Chen YQ, McCauley M, Gamble T, Hosseinipour MC, Kumarasamy N, et al. Prevention of HIV-1 Infection with Early Antiretroviral Therapy. N Engl J Med. 2011.365(6):493-505.

8. Rodger A. HIV transmission risk through condomless sex if HIV+ partner on suppressive ART: PARTNER Study. 21st CROI. Boston; 3-6 March 2014. Oral late breaker abstract 153LB. Available from: http://www.croiwebcasts.org/console/ player $/ 22072$

9. Diez M, Bleda MJ, Varela JA, Ordo-ana JR, Azpiri MA, Vall M, et alTrends in HIV testing, prevalence among first-time testers, and incidence in most-at-risk populations in Spain: the EPI-VIH Study, 2000 to 2009. Euro Surveill. 2014;19(47):pii=20971.

10. Giuliani M, Vescio MF, Latini A, Palamara G, Pimpinelli F, Donà $M G$, et al. Continuous increase in HIV-1 incidence after the year 
2000 among men who have sex with men in Rome: insights from a 25-year retrospective cohort study. Euro Surveill.

2014;19(47): pii=20969.

11. Kivimets K, Uusküla A. HIV testing and counselling in Estonian prisons, 2012 to 2013: aims, processes and impacts. Euro Surveill. 2014;19(47):pii=20970

12. Rayment M, Thornton A, Mandalia S, Elam G, Atkins M, Jones $\mathrm{R}$,et al. HIV testing in non-traditional settings--the HINTS study: a multi-centre observational study of feasibility and acceptability. PLoS One. 2012;7(6):e39530. ttp://dx.doi. org/10.1371/journal.pone.0039530

13. Brady M. Home HIV sampling linked to national HIV testing campaigns: a novel approach to improve HIV diagnosis, abstract 021 . Third Joint Conference of BHIVA and BASHH. Liverpool; April 2014. Available from: http://www.bhiva.org/ documents/Conferences/2014Liverpool/Presentations/140403/ MichaelBrady.pdf

14. European HIV testing week. The HIV in Europe initiative. Available from: http://www.hivtestingweek.eu/

15. UNAIDS. An ambitious treatment target to help end the AIDS epidemic. Available from: http://www.unaids.org/en/ resources/documents/2014/90-90-90 